eISSN: 2659-6482

DOI: https://doi.org/10.14201/pmrt.19022

\title{
EL COUNTRY SE VA A LA GUERRA: EL APOYO A LA GUERRA DE VIETNAM Y EXPRESIÓN DEL MOVIMIENTO PROBÉLICO EN ESTADOS UNIDOS
}

\section{Country Music goes to War: The Support of Vietnam War and the Expression of the Pro-War Movement in the United States}

\author{
Juan Andrés GARCÍA MARTÍN \\ Universidad Rey Juan Carlos \\ juan.garcia.martin@urjc.es
}

RESUMEN: La guerra de Vietnam abrió una profunda herida en la sociedad estadounidense a través de la división de opiniones que generó. Muchos estadounidenses se opusieron a la escalada bélica y así quedó de manifiesto en una ingente producción musical de protesta. Frente a esta idea, un porcentaje no menos desdeñable de norteamericanos constituyó un movimiento probélico que apoyó la contienda en defensa de los valores que atesoraba la sociedad estadounidense, manifestando estos posicionamientos a través de varias obras musicales, especialmente copiosas en el género country.

Este artículo investiga la razón del apoyo que este género brindó, así como un análisis del mismo a través de una selección de cantautores y canciones, acompañado de una detallada documentación bibliográfica sobre la cuestión. A través de ello queremos demostrar en qué medida el conflicto fraccionó a la sociedad estadounidense durante las décadas de 1960 y 1970 y cómo sus defensores emplearon la música para enarbolar la bandera de la intervención militar norteamericana en el sudeste asiático tales como la defensa de la democracia, el rechazo a la expansión del comunismo, el valor de los combatientes y la creación de un enemigo casa, que de ahora en adelante podemos denominar como anti-América. 
JUAN ANDRÉS GARCÍA MARTÍN

EL COUNTRY SE VA A LA GUERRA: EL APOYO A LA GUERRA DE VIETNAM Y EXPRESIÓN DEL MOVIMIENTO PROBÉLICO EN ESTADOS UNIDOS

Palabras clave: Guerra de Vietnam; música; canción; cantautor; country; probélico.

ABSTRACT: The Vietnam War opened a deep wound into American society through the division that it created. Many Americans opposed the escalating conflict, which was portrayed in an enormous amount of protest music. To counter this opposition, a high percentage of Americans formed a pro-war movement that supported the war in defense of the most valuable principles treasured by American society, showing these ideals through several songs, especially numerous among country music.

This paper analyzes the reasons that country music supported the war, as well as analyzes it through a selection of songwriters and their themes as a source, alongside a detailed book documentation about the topic. Through this perspective, we demonstrate how the conflict fractured the American society during the 1960s and 1970s and how its proponents used music to back the American intervention in Southeast Asia. These songs praised soldiers' courage, villainized dissenters as the anti-American enemy at home, and supported the defense of democracy and the rejection of Communist expansion.

Keywords: Vietnam War; music; song; song-writer; country; pro-war.

\section{PLANTEAMIENTO. OBJETO DE ESTUDIO Y FUENTES}

Constituye una idea generalmente aceptada que la música es un vehículo de transmisión emocional. Al mismo tiempo, sin embargo, puede adquirir un significado racional en cuanto refleja ciertas ideas y planteamientos sociopolíticos. El presente estudio pretende analizar el papel desempeñado por la música country como apoyo a la guerra de Vietnam durante las décadas de 1960 y 1970. Lo haremos no sólo como reflejo y apoyo de la sociedad estadounidense al conflicto, sino como contrapeso a la canción protesta contraria a la participación norteamericana en dicha contienda. Es, además, objeto de investigación la temática reflejada y con la que se argumenta la participación bélica y la uniformidad del género en este devenir. Debido al espacio disponible para una investigación de estas características, no es menester en este trabajo analizar en profundidad los movimientos probélico y antibelicista, otros géneros musicales, así como tampoco otras formas de expresión artísticas ni cada uno de los subgéneros que integran la música country.

De acuerdo con el etnomusicólogo estadounidense Alan P. Merriam, una canción que exprese estas ideas desempeña varios cometidos. Primeramente, 
encarna la función del refuerzo de la conformidad a las normas sociales en tanto que apoya la intervención militar estadounidense en Vietnam y critica mediante la estigmatización a aquellos que se oponen a dicha participación. Además, contribuye a la continuidad y estabilidad de una cultura al ejercer de vehículo transmisor de la realidad histórica de un momento específico, ejerciendo de cámara fotográfica sin imágenes, pero con palabras. Y, por último, obtiene una función integradora de la sociedad al actuar como nexo de unión alrededor del cual los miembros de aquélla participan en actividades que requieren cooperación y coordinación grupal, tales como conciertos, campañas electorales o manifestaciones.

Aplicando una observación más minuciosa, observamos que el género más prolífico en su apoyo a la guerra de Vietnam fue la música country, aunque no el único en hacerlo. Especialmente arraigada en los estados meridionales y del Medio Oeste de Estados Unidos, en ellos se produjo una notable amalgama ideológica durante la década de 1960 que llevó a apoyar la participación en la contienda asiática como una vigilancia de los valores estadounidenses, al mismo tiempo que se rechazaba la intervención del gobierno federal en la implantación de derechos civiles para la ciudadanía afroamericana y la consiguiente igualdad racial.

Por lo tanto, la música country ofrece una producción notable de obras que, a través de la defensa de ciertos ideales, justifican la participación estadounidense en la contienda. Para el presente estudio, hemos realizado una selección de dichas composiciones, ya que un análisis de la totalidad resulta inabordable. En cuanto a la defensa de la participación estadounidense en el conflicto, ésta puede ser sometida al microscopio a través de un análisis temático de las obras compuestas que hemos seleccionado, pero este uso de fuentes primarias puede antojarse insuficiente. Por ello, a la hora de llevar a cabo este cometido es necesario contar con otro tipo de fuentes que permitan contextualizar obra y cantautor. En esta investigación, en consecuencia, hemos contado con varias autobiografías de cantautores country. Los escritos de Merle Haggard y Mel Tills permiten entender los pensamientos, motivaciones y vivencias personales de los propios compositores. A pesar de estas memorias, la producción autobiográfica es limitada, por lo que hemos acudido a estudios e investigaciones biográficas que han resultado igualmente provechosos. Es el caso del estudio de Michael Streissguth sobre Eddy Arnold (2009); de Diane Diekman acerca de Marty Robbins (2012); David Cantwell sobre el propio Merle Haggard (2013); o más recientemente de Mary G. Hurd sobre Kris Kristofferson (2015).

La limitación de estudios concretos sobre los cantautores country obliga a acudir a obras de carácter más general, en busca de contextualización y evolución del género. Por ejemplo, el movimiento probélico en el que se engloba este estilo ha sido objeto de estudio de la profesora del UCD irlandés Sandra Scanlon. Un análisis más concreto sobre la propia música country estadounidense puede 
observarse en las obras enciclopédicas y por lo tanto generalistas dirigidas por Irwin Stambler y Grelun Landon (1997) y Paul Kingsbury (1998) respectivamente. El estudio más completo al respecto ha sido elaborado por Bill C. Malone y Tracey E. W. Laird (2018), reedición de la obra en su $50^{\circ}$ aniversario y que, a través de una actualización constante, observa la evolución del género en el s. XX.

Por otra parte, apenas encontramos referencias a las inquietudes patrióticas y probélicas del género en tres obras. Por un lado, el estudio de Charles K. Wolfe y James E. Akenson (2005), en el que se traza la visión de la música country ante diversos conflictos. Sorprendentemente, este estudio omite cualquier referencia al apoyo de la música country a la guerra de Vietnam, siendo sin embargo de utilidad para comprender el posicionamiento del género durante otros momentos de la Guera Fría. Por otro lado, las obras de K. Hillstrom y L. C. Hillstrom (1998) y Stewart O’Nan (1998) suponen una aproximación musical, literaria y cinematográfica al conflicto. Con más concreción, James E. Perone (2001) ha aportado una compilación musical del periodo que supone un punto de partida nada desdeñable para la investigación sobre la cuestión.

Finalmente, la historiografía española se ha caracterizado por un escaso interés ante un género lejano. El renacimiento de la música folk acaecido durante las décadas de 1950 y 1960 ha sido objeto de estudio por parte de A. Fernández Ferrer (2007). En cuanto al intervalo temporal que nos ocupa, los estudios más interesantes han sido realizados por Alfonso Trull (1994 y 1995) y Luis Fernando Iturrate Cárdenes (2003), quienes han estudiado la música country y los diferentes géneros vinculados al conflicto asiático respectivamente.

Previo al comienzo del estudio, creemos necesario realizar tres precisiones terminológicas. A pesar de la riqueza de la lengua castellana, un tema tan concreto como el que se estudia puede incurrir en reiteraciones. Por un lado, en ocasiones nos referiremos a los partidarios de la guerra de Vietnam como «halcones», sin relación biológica o con el arte de la cetrería alguna pero sí caracterización que suele dividir a todo gobierno entre sus componentes más agresivos y más pacíficos. Por otro lado, traduciremos America por Estados Unidos, evitando utilizar un concepto geográfico para un país en cuestión. Por último y a fin de apoyar las ideas que expresamos en este estudio, hemos decidido puntualizar el lugar y fecha de nacimiento de todos aquellos cantantes de quienes disponíamos de información nada más referenciarlos. Con ello, constatamos sus orígenes en estados meridionales, del Medio Oeste o en regiones definidas por flujos migratorios con ascendencia de los dos primeros. 
JUAN ANDRÉS GARCÍA MARTÍN

EL COUNTRY SE VA A LA GUERRA: EL APOYO A LA GUERRA DE VIETNAM Y EXPRESIÓN DEL MOVIMIENTO PROBÉLICO EN ESTADOS UNIDOS

\section{LA DÉCADA DEL CAMBIO: UNA INTERVENCIÓN LEJANA, UNA CASA DIVIDIDA}

El comienzo de la Guerra Fría supuso la división del globo en zonas de influencia repartidas entre las potencias vencedoras en la Segunda Guerra Mundial. EE.UU. y Unión Soviética, campeones de dos modelos antagónicos, convirtieron el mundo en un tablero de ajedrez en el que el crecimiento de uno sólo se podía llevar a cabo mediante la injerencia en la esfera ajena. El bloqueo de Berlín entre 1948 y 1949, la guerra de Corea o la crisis de los misiles en Cuba revelaron no solo la tensión vecinal entre ambos colosos, sino también el crecimiento de un sentimiento de inseguridad dentro de Estados Unidos. Éste quedó de manifiesto durante la década de 1950 a través de una purga de elementos comunistas, considerados como una infección potencial y en consecuencia una amenaza para el estado natural del país: libertades, individualismo, democracia y capitalismo.

En este orden bipolar, el sistema colonial resultaba caduco y progresivamente, las potencias europeas asistieron al desmoronamiento de sus imperios. Uno de estos territorios era la colonia francesa de Indochina. Después de ser ocupada por los japoneses durante la conflagración mundial, la metrópoli intentó imponer su control nuevamente, con lo que desencadenó un largo conflicto (1946-1954). En la paz de Ginebra de 1954, Francia sancionó la pérdida de su colonia, dividida ahora en varios estados, entre los que la franja costera dio lugar a la República Democrática de Vietnam del Norte, comunista, y la República de Vietnam, bajo tutela estadounidense, nuevo guardián occidental en la región. Después de la caída de China y de Vietnam del Norte en manos comunistas en un breve espacio temporal, los peores presagios estadounidenses ante la expansión comunista parecían confirmarse. Si el sudeste asiático caía, según la lógica estadounidense, Australia y Japón serían los siguientes en sucumbir, con lo que los retoques fronterizos de Ginebra, transitorios, fueron convertidos en permanentes por la República de Vietnam y EE.UU., que desplazaba así su frontera estratégica a la zona.

Durante los años siguientes, EE.UU. incrementó su apoyo militar y económico a la República de Vietnam, pero no sería hasta la presidencia de Lyndon B. Johnson, cuando la Casa Blanca apostó por una intervención más enérgica en la región. Este refuerzo venía acompañado de un reguero de bajas estadounidenses y en 1968 perecían alrededor de 400 estadounidenses cada semana, cifras que hacían que la sociedad norteamericana se cuestionara la idoneidad de una guerra lejana ${ }^{1}$. Así lo constataban las crecientes revueltas estudiantiles y manifestaciones que recorrían el país exigiendo el final de una intervención que interpretaban ya

1. Schreiber, E. M. (1973). «Opposition to the Vietnam war among American University Students and Faculty», The British Journal of Sociology, Vol. 24, n. 3 (September) 288-289. 
no sólo como innecesaria y abusiva, sino como un conflicto sufragado a costa de las vidas de las clases menos pudientes y de minorías raciales, convertidas en verdadera carne de cañón ${ }^{2}$.

El cuestionamiento de esta agresiva política exterior vino acompañado de una crítica feroz al orden racial interno del país que, dicho sea de paso, no era nuevo. Desde finales del s. XIX se había establecido la segregación racial a través de una serie de medidas legales conocidas como leyes Jim Crow, las cuales restringían la vida ciudadana plena de la población afroamericana. En este contexto, surgieron varias asociaciones dispuestas a erradicar este sistema a través de la igualdad de derecho al voto y el fin de la segregación racial en lugares públicos.

Presidentes como Harry Truman primero, Dwight Eisenhower después y por último J. F. Kennedy ya habían tratado de integrar a la población afroamericana de manera progresiva, pero se toparon con la creciente oposición de los estados sureños, bastiones de la separación entre blancos y negros. No sería hasta la presidencia de L. B. Johnson (1963-1968) cuando el sistema quedó derogado a través de la Ley de derechos civiles (1964) y la Ley de derecho al voto (1965).

El cuestionamiento de los dos axiomas vertebradores de la política norteamericana hasta la fecha se produjo a cargo de una nueva generación de estadounidenses que, nacidos entre las postrimerías de la Gran Depresión y los inicios de la Guerra Fría, buscaban tanto liberarse de las ataduras sociales con las que el rígido conservadurismo de la posguerra mundial encorsetaba su desarrollo personal como derribar el orden nacional e internacional que lo amparaba. Esta generación, conocida como beat, y sus herederos hippies, unieron los cabos de ambos argumentos para desarrollar un seísmo en forma de movimiento de protesta que sacudió los cimientos de la sociedad estadounidense

Sin embargo, conviene desterrar la idea de que todo el país compartía estas inquietudes. En las elecciones presidenciales de 1964, L. B. Johnson derrotó al candidato republicano Barry Goldwater. Las habilidades literarias de este senador por Arizona demostraban un ferviente anticomunismo ${ }^{3}$, lo que en la práctica se traducía en un deseo de finiquitar los programas sociales demócratas, pero también de una actitud más enérgica en el Sudeste asiático. Si bien Johnson aplastó a su rival en los comicios, Goldwater obtuvo 27 millones de votos, además de arañar su estado natal y cinco estados del Sur profundo (Luisiana, Misisipi, Alabama, Georgia y Carolina del Sur).

2. Hillstrom, Kevin y Hillstrom, Laurie Collier (1998). The Vietnam experience. A concise encyclopedia of American Literature, Songs and Films, p. 113, Westport: Greenwood Press.

3. Goldwater, Barry (1961). The conscience of a conservative. New York: MacFaddenBartell Co. 
Cuatro años después, tuvo lugar una nueva cita electoral en un clima de protesta y caos social a raíz de la guerra de Vietnam. Los asesinatos del candidato demócrata R. F. Kennedy y el activista de derechos civiles M. L. King, críticos con el conflicto, contribuyeron a enrarecer aún más el ambiente. El presidente L. B. Johnson declinó presentarse a la reelección por el Partido Demócrata, haciéndolo en su lugar Hubert Humphrey. Hasta la fecha vicepresidente y con un marcado carácter continuista, se mostraba favorable de detener temporalmente los bombardeos sobre Vietnam a fin de negociar con los norvietnamitas y ganar rédito electoral. Por su parte, el Partido Republicano encontró su caballo ganador en Richard Nixon bajo el lema de «ley y orden», además de una promesa de retirada con honor de Vietnam. Éste contaría con gran parte de sus apoyos entre las clases medias blancas, muchos de ellos procedentes de la migración interior desde los estados sureños y del Medio Oeste en los años previos. Herederos conservadores, se revelaban distantes con las elites liberales, minorías y pobres, al mismo tiempo que buscaban proteger sus propiedades frente a cualquier subversión. De este modo, mostraban su hostilidad hacia la Gran Sociedad y fríos hacia los derechos civiles, el feminismo y los movimientos estudiantiles ${ }^{4}$.

Por último, hizo acto de presencia un dúo electoral compuesto por George Wallace, ex gobernador de Alabama, y el general Curtis Le May. Entre las líneas maestras de su programa, se incluía el mantenimiento de la segregación racial y una intervención más vigorosa en Vietnam. No es de extrañar que, si bien Nixon se alzó con el triunfo en la cita electoral, Wallace obtuviera diez millones de votos traducidos en 45 votos electorales correspondientes a los cinco estados del Sur Profundo, prácticamente los mismos que había obtenido Goldwater. Estos estados, sensibles a su retórica segregacionista, contaban con una amplia población cristiana que rechazaba cualquier amenaza a los valores tradicionales del país e identificaban por igual como perturbadores de su estilo de vida a detractores de la guerra de Vietnam y defensores de los derechos civiles de la población afroamericana.

Las elecciones, en consecuencia, no fueron más que un reflejo de la dinámica en la que se movía el país. Por aquel entonces y al amparo de la guerra de Vietnam, el conservadurismo estadounidense elaboraba un discurso cada vez más agresivo contra los detractores del conflicto, denigrando a los liberales, a quienes tildaban de antipatriotas 5 . En mayo de 1967, Nueva York vio como una marcha de 70.000 personas recorría la Quinta Avenida en apoyo de la guerra de Vietnam. En la

4. La Chapelle, Peter (2007). Proud to be an Okie. Cultural politics, country music, and migration to Southern California, p. 10, Berkeley: University of California Press.

5. Scanlon, Sandra (2013). The pro-war movement. Domestic support for the Vietnam war and the making of Modern American conservatism, pp. 7-15, Amherst: University of Massachusetts Press. 
primavera de 1970, varios miles de manifestantes se congregaron periódicamente durante dos semanas en Wall Street intentando contrarrestar al movimiento antibélico que exhibía músculo por todo el país, como acredita la manifestación acaecida en noviembre del año anterior en Washington. Y es que, a la sazón, un $55 \%$ de los norteamericanos consideraban la guerra de Vietnam un error ${ }^{6}$. Si bien esta cifra era importante, no resultaba abrumadora.

\section{MÚSICA PARA PROTESTAR}

La efervescencia que recorría el país durante la década de 1960 encontró diferentes formas de manifestación artística. Literatura y música no fueron ajenos al terremoto que sacudía Estados Unidos. En el caso musical, se había producido desde la década de 1940 un repunte del género folk. Éste no hacía sino reivindicar ritmos y melodías que evocaban a las clases obreras y populares. Numerosos cantautores como Woody Guthrie o Pete Seeger no tardaron en recuperar estos elementos como vehículos de expresión de sus inquietudes progresistas en una atmósfera de rebeldía contagiosa que ejercía como una auténtica argamasa social. Joan Baez, Bob Dylan, Leonard Cohen o Harry Belafonte constituyen tan solo algunos ejemplos de este ambiente febril en el que la canción protesta alcanzaba así su mayoría de edad, para a continuación romper barreras nacionales, ideológicas e incluso introducirse en varios subgéneros musicales. De este modo, la canción-protesta supone un aliento reivindicador que vislumbra un horizonte a conquistar. El trayecto hasta entonces, penoso, se supera gracias a la esperanza de un mundo mejor al final de aquél.

La canción-protesta, enarbolada como una reclamación, no es en absoluto patrimonio de los sectores progresistas. Caeríamos en una generalización al así considerarlo ya que, como hemos constatado, desde 1965 hasta el final del conflicto en 1974, el movimiento probélico se mostró considerablemente activo en sus reivindicaciones. Llegados a este punto, nos planteamos dos cuestiones. ¿Qué géneros apoyaron la intervención en el conflicto? y, en consecuencia, ¿qué artistas se mostraron dispuestos a ofrecer su imagen y su música por esta causa? En respuesta a la primera pregunta, cabe recalcar el apoyo de la música de carácter militar por simpatía gremial, pero no únicamente. Al ser el conservadurismo estadounidense quien había brindado su mayor apoyo a la contienda en su rechazo al comunismo, no resulta extraño que la música desarrollada en aquellas regiones con menor ímpetu progresista sean las que apoyaban la intervención militar. La

6. Su, Yang y McAdam, D. (2002, October). «The War at home. Antiwar protests and Congressional Voting, 1965-1973», p. 698, American Sociological Review, Vol. 67, No 5, p. 697-699. 
música a la que hacemos referencia es el country, imbuido en sus componentes mayoritarios de un espíritu conservador ${ }^{7}$.

El Sur es, por lo tanto, la región a la que nos referimos y la música country formaba parte de su idiosincrasia desde los tiempos de la Guerra Civil, un siglo atrás ${ }^{8}$. Agrarios y más aislados social y económicamente, pero interconectados en pequeñas comunidades familiares dispuestas a compartir su patrimonio cultural, los estados meridionales constituían una suerte de creciente fértil para el desarrollo del género. Éste, no obstante, acabó por comercializarse y extenderse. Primero, a otros estados rurales del Medio Oeste durante la década de 1920, gracias a la acción de cantautores como Jimmie Rodgers, Hank Williams o el grupo The Carter Family. De este modo, consiguió romper parcialmente su aislamiento, pero también incorporar nuevas melodías de tradición anglosajona, así como cantos religiosos. Y más adelante, esto es, a raíz de los intercambios migratorios acaecidos durante la Gran Depresión y la Segunda Guerra Mundial, a áreas urbanas del norte, donde de nuevo tuvo que adaptarse a los gustos de otras regiones ${ }^{9}$. En los albores de la Guerra Fría, por lo tanto, el género country gozaba de buena salud.

Cuando en el verano de 1964 el presidente Lyndon B. Johnson utilizó un incidente naval en el golfo de Tonkín para apresurar la intervención norteamericana en Vietnam, pronto comenzaron a producirse las primeras opiniones musicales a favor y en contra de la misma. Bajo la presidencia de J. F. Kennedy ya se habían compuesto algunas melodías contrarias a cualquier intervención. De manera simultánea, Bob Dylan en 1963 y Barry McGuire en 1964 también habían dejado constancia de su preocupación ante la carrera nuclear entre soviéticos y estadounidenses a través de «Hard Rain» y «Eve of Destruction» respectivamente. Un año después, fue Tom Paxton quien cuestionó los argumentos presidenciales para arrancar la escalada bélica en el sudeste asiático. Quienes apoyaban el conflicto no podían quedarse de brazos cruzados ante la ofensiva de los detractores. Las primeras tonadas que defendían la acción gubernamental no aparecieron hasta que las primeras tropas estadounidenses aterrizaron en el sudeste asiático en $1965^{10}$. En este mismo año, por ejemplo, tuvo lugar en la Universidad de Vanderbilt (Tennessee) un concierto de música country a cargo de Chet Atkins, Skeeter Davis y Eddy Arnold. La elección de Nashville como sede del concierto no era aleatoria en absoluto, ya que era considerada por muchos como el epicentro del género

7. Hurd, Mary G. (2015). Kris Kristofferson, p. 73, Londres: Rowman \& Littlefield.

8. Wolfe, Charles K. y Akenson, James E. (2005). Country Music goes to war, p. 5, Lexington: The University Press of Kentucky.

9. Malone, Bill. C. y Laird, Tracey E. W. (2018). Country Music USA, pp. 3-4 y 208-209, Austin: University of Texas Press. Press.

10. Perone, James E. (2001). Songs of the Vietnam Conflict, p. 72, Westport: Greenwood 
JUAN ANDRÉS GARCÍA MARTÍN

EL COUNTRY SE VA A LA GUERRA: EL APOYO A LA GUERRA DE VIETNAM Y EXPRESIÓN DEL MOVIMIENTO PROBÉLICO EN ESTADOS UNIDOS

country $^{11}$, que de este modo comenzaba a posicionarse como estilo a favor del conflicto. Ahora bien, aquellos que defendían la intervención bélica en el sudeste asiático, ¿qué ideas esgrimían en su defensa?

\section{LA GUITARRA TOCA A REBATO}

\subsection{En defensa de las barras y estrellas}

En el devenir de la Guerra Fría, Estados Unidos desplazó su frontera al sudeste asiático por lo que, en teoría, cualquier amenaza en dicha región se entendía como propia. En plena fiebre mccarthysta durante la década de 1950, varios cantantes country habían mostrado su rechazo a la Unión Soviética, pues entendían que el comunismo atacaba la forma de vida de quienes escuchaban o practicaban dicho género. Patriotismo, individualismo, recelo al intervencionismo gubernamental y Cristianismo protestante constituían los pilares ideológicos de la comunidad country. La democracia era un bien propio anglosajón a preservar y el totalitarismo soviético un ambiente irrespirable. En consecuencia, el retrato de la Unión Soviética resulta terrorífico, toda vez que era entendida como una amenaza a todos los efectos. A la propiedad privada y por lo tanto a las libertades individuales, como por ejemplo cantaban el dúo Lullu Belle and Scotty (Carolina del Norte, 1913 y 1908 respectivamente) en «I'm No Communist» (1952), al tiempo que daban a entender su preocupación por la infiltración de agentes comunistas. Hacia la religión, como constata «They Locked God outside the Iron Curtain» (1952), obra de Little Jimmy Dickens (Virginia, 1920). O incluso al adoctrinamiento de la sociedad, como sugiere Red River Dave, también conocido como Dave McEnery (Texas, 1914), en «Red Deck of Cards» (1954).

Ante semejante desafío, el papel policial estadounidense allá donde los soviéticos estaban más próximos, esto es Berlín y Corea, estaba más que justificado. Cual instrumento y martillo divino, Estados Unidos podía intervenir donde su seguridad se viera amenazada y para ello, el recién creado armamento nuclear podía resultar una herramienta disuasoria con cuyo monopolio temporal el país se sentía seguro. El optimismo y confianza en la victoria final de Estados Unidos se aprecia tanto en los avisos lanzados a Stalin por parte de Hank Williams (Alabama, 1923) en «No, No Joe» (1950) o por Roy Acuff (Tennessee, 1903) en «Advice

11. Cabe citar dos ejemplos que certifican esta afirmación. Nashville cuenta desde 1964 con el Country Music Foundation, organización dedicada a la preservación del género que cuenta con uno de los principales archivos sobre la materia. Del mismo modo, anualmente se celebra en Nashville el International Country Music Conference (ICMC). Sobre cómo Nashville se convirtió en el centro de la música country, recomendamos la siguiente obra: Hinton, Brian (2000). Country Roads. How Country Came To Nashville. London: Sanctuary Publishing. 
Joe» (1951), como en el fervor patriótico desatado en varios temas. Por ejemplo, Jimmie Osborne (Kentucky, 1923) ya anticipaba la victoria antes de que la Guerra de Corea concluyera en «Thank God for Victory in Korea» (1950) y «The Voice of Free America» (1951), loa a la política de contención al comunismo del presidente Truman. En la misma línea se manifiesta Elton Britt (Arkansas, 1913) en «The Red We Want is the Red We Got in the Old Red, White and Blue» (1950), para quien no hay ningún comunista aceptable. El mensaje era claro: la infalibilidad militar estadounidense como base de su confianza frente al comunismo.

Esta inquebrantable fe dio paso a cierta frustración por la acción del propio gobierno demócrata durante la década de 1960. La crisis de los misiles en Cuba fue entendida como un revés ante la Unión Soviética, al tiempo que ésta parecía fortalecida desde que rompiera el monopolio atómico en 1949. Además, la progresiva intervención del gobierno federal para poner fin a la segregación racial acabó por crear desconfianza hacia aquél. Esta perspectiva quedó reflejada en «Dear Ivan» (1961), cantada por Jimmy Dean (Virginia, 1928). En ella Dean invitaba a un ciudadano ruso corriente a través de una carta recitada a sentarse frente a frente y solucionar sus diferencias sin gobernantes de por medio, a cambio de enseñarle las bondades de la vida estadounidense que el mismísimo Thomas Jefferson firmaría: individualismo, familia, religión, espíritu agrario, mínima participación gubernamental...

El temor anticomunista se mantuvo durante la década de 1960. Sirva como ejemplo Jimmie Davis (Luisiana, 1899), cantante country y gobernador de Luisiana, que llegó a afirmar en un discurso en 1962 que los soviéticos prometían carne de ternera y libertad, pero en verdad traían carne de caballo y miseria. En la misma línea se manifestaba el reverendo Alfred G. Karnes (Virginia, 1891), antiguo cantante country, quien en sus sermones identificaba a la Unión Soviética con Gog, personaje apocalíptico del libro de Ezequiel ${ }^{12}$. Resulta evidente, por ende, el rechazo que suscitaba entre dicha comunidad la expansión de la URSS y la amenaza que ello suponía.

\section{2. ¿Por qué luchar?: el buen sacrificio}

La tímida participación en Vietnam iniciada bajo el gobierno de J. F. Kennedy dio lugar a una intervención más enérgica bajo el mandato de su sucesor, L. B. Johnson. De los 9.000 norteamericanos presentes en Vietnam en 1962, se pasó a 150.000 en 1965, cifra duplicada un año después, y a medio millón en $1968^{13}$.

12. Wolfe, Charles K. y Akenson, James E. (2005). Country Music goes to war, p. 143-149, Lexington: The University Press of Kentucky.

13. Jones, Maldwyn A. (1995). Historia de Estados Unidos, p. 510, Madrid: Cátedra. 
Cuando el conflicto tocó a su fin en 1974, habían fallecido 58.000 estadounidenses en las selvas del sudeste asiático. Semejante sangría era difícil de explicar. A ojos de los detractores resultaba injustificable. Sin embargo, para los halcones, si bien la guerra no era el mejor de los escenarios deseable debido a su crueldad, aquélla era aceptada como un mal necesario e inevitable en defensa de unos determinados valores.

En 1964, el dúo Charlie Moore y Billie Napier (Carolina del Sur y Virginia respectivamente, 1935) había reversionado "God please Protect America», escrita por Jimmie Osborne en 1950 como plegaria durante la Guerra de Corea. La canción es una oración a Dios para proteger a los Estados Unidos y animar a rezar por las tropas en las primeras semanas de la invasión de Corea. Catorce años después, el dúo sureño adaptaba la canción a una nueva intervención militar. Varios años más tarde, en 1972, el sociólogo Jens Lund identificó en «Hello Vietnam», compuesta siete años atrás por Tom T. Hall (Kentucky, 1936) e interpretada por Johnnie Wright (Tennessee, 1914) como la primera canción country en apoyo a la intervención militar estadounidense en Vietnam. Como la obra revisada por Moore y Napier es una reedición de la melodía de Osborne, aceptaremos la tesis de Lund, tal y como sugiere Perone. En «Hello Vietnam», el sacrificio en aras de la democracia es el tema recurrente de la obra, ya que en ella Hall retrata a un joven norteamericano que se despide de su hogar y su amada, para saludar a la nueva tierra - Vietnam - en la que va a luchar en defensa de la libertad sin dudarlo:

We must stop Communism in that land

Or freedom will start slipping through our hands

Lanzada en el verano de 1965, la canción fue un éxito inmediato, al colocarse en las listas de obras de música country más escuchadas durante varias semanas consecutivas, tres de las cuales ocupó la primera posición. Su mayor novedad residía en su amalgama de piano y guitarra metálica como pedal, algo que a muchos seguidores del género les resultaba todavía extraño de digerir ${ }^{14}$. Sin embargo, no sería la única vez que Tom T. Hall prestaba su ingenio para la causa probélica. En «What We're Fighting for» (1965), Hall justifica la intervención militar como justa, conectándola con las participaciones estadounidenses en la Segunda Guerra Mundial o en Corea, de nuevo en boca de un soldado que comunica sus sentimientos sobre la guerra en una carta escrita a su madre. La obra fue interpretada por Dave Dudley (Wisconsin, 1928), un antiguo jugador de baseball reconvertido a cantante country, cuya potente voz le permite mantener una melodía brillante en la que no se atisba pena, sino el orgullo de un soldado al servir a su país.

14. Perone, James E. (2001). Songs of the Vietnam Conflict, pp. 75-77, Westport: Greenwood Press. 
1965 fue un año, sin duda, hiperactivo para la composición de música probélica. Ello se debe tanto al desembarco de tropas en Vietnam como al crecimiento exponencial de las protestas antibélicas. Quienes apoyaban el conflicto respondieron incrementando su producción musical en defensa de la causa. Dave McEnery compuso «It's for God and Country and You, Mom» a finales de 1965. No era la primera ocasión que McEnery ensalzaba las hazañas estadounidenses, ya que en 1937 había compuesto «Amelia Earhart's Last Flight», poco después de la desaparición de la aviadora. La canción escrita en 1965 fue versionada poco después por Ernest Tubb (Texas, 1914), cosechando escaso éxito por coincidir en el tiempo con la producción de Tom T. Hall, auténtica gallina de los huevos de oro a la sazón. A ello, se unía que Tubb, barítono que superaba el medio siglo de edad, carecía de credibilidad interpretativa para dar vida en la letra a un joven recluta que escribía a su madre.

En la misma línea se manifestó Johnnie Wright, quien editó también «Keep the Flag Flying», su segunda tonada probélica del año. De nuevo con influencias del piano de Floyd Cramer en forma de arpegios entre cada estrofa y con un tempo pausado, esta obra es un vals en la que el cantante es un soldado describe cómo un compañero de armas ha muerto a causa del disparo de un francotirador, cómo informa a la familia del fallecido de la pérdida y cómo, a pesar de ello, el recluta mantiene su promesa de ondear la bandera estadounidense ${ }^{15}$. Para el género country, Estados Unidos siempre prevalece.

Un año después, Harlan Howard (Michigan, 1928), un antiguo paracaidista con ida y vuelta de Michigan a Tennessee, pasando por California, compuso "The Minute Men (Are turning in their Graves)», obra en la que incidía en la teoría del dominó, con lo que la presencia militar norteamericana era requerida en el sudeste asiático. Sin embargo, ante las crecientes protestas que florecían en EE.UU., Howard recurre a la tan innovadora como cuestionable idea de asumir que los padres de la nación, George Washington y Thomas Jefferson, apoyarían el conflicto y se avergonzarían de la actitud del movimiento antibélico. Con ello, contribuye a estigmatizar a aquél, al mismo tiempo que traza una línea directa entre la fundación del país y su acción exterior, cuasi providencial. La obra fue grabada por el guitarrista Stonewall Jackson (Carolina del Norte, 1932) en una versión que ofrece elementos distintivos del género country más áspero través del uso del banjo, si bien también incluye un marcado ritmo militar a través del uso de percusión.

A medida que el conflicto avanzaba, los cantantes country mantuvieron sus argumentos, intentando justificar los objetivos de la intervención militar. «Is This

15. Perone, James E. (2001). Songs of the Vietnam Conflict, pp. 80-81, Westport: Greenwood Press. 
a Useless War?» fue compuesta por Charlie Moore y Bill Napier en 1966 para justificar el conflicto como una batalla por la libertad. No era la primera vez que el dúo sureño apoyaba el conflicto, ya que dos años antes habían adaptado «God please Protect America» al conflicto vietnamita, como se ha señalado anteriormente. En esta ocasión, esta nueva composición era parte de un amplio álbum titulado Country Music Goes to Viet Nam, diseñado para apoyar la guerra y que rezuma patriotismo desde su mismo envoltorio: los colores rojo, azul y blanco tiñen la caja del mismo junto a varios logotipos de las fuerzas armadas estadounidenses. Además de «Is this a useless War?», Moore y Napier introdujeron «I'll Be Home», una obra en forma de carta escrita inconclusa por un soldado a su amada, que percibe la muerte de aquél, y «Have I Come To Die?», canción acompasada como un vals en la que un soldado encuentra a su amada con otro hombre en su regreso al hogar, por lo que acepta su destino y muere, ya que ¿no es sino por el bienestar de su familia por lo que ha ido a combatir?

Por último, en toda guerra resulta necesario mantener la moral alta entre quienes la apoyan. Además de denostar al rival, los defensores de la participación militar en Vietnam ensalzaban el coraje de los combatientes. Marty Robbins (Arizona, 1925) así lo hizo en «Private Wilson White» (1966), ya que se trata de la historia de un soldado a quien, en su defensa de la libertad, solo pudo ser abatido por siete balas. Pat Boone (Florida, 1934) también mostró su apoyo a los soldados que luchaban en Vietnam a través de un álbum titulado «Wish You Were here, Buddy» (1966), ensalzando el coraje de los combatientes en sus letras. A esta obra, sin embargo, aludiremos más adelante por una sus referencias temáticas.

Después del periodo de hiperactividad comprendido entre 1965 y 1966, desde 1967 decrece la producción de música country en apoyo de la participación militar estadounidense. En su lugar, aparecen otras temáticas como la figura de los veteranos o, sobre todo, la crítica al movimiento antibelicista que cobraba cada vez más fuerza en el país. Por último, cabe citar a Autry Inman (Alabama, 1929), quien compuso «The Ballad of the two Brothers» (1968), pieza en forma de cuatro cartas en la que contrapone la acción simultánea de dos hermanos: la primera, de Bud el soldado que combate; la segunda, de Tommy, el activista pacifista; la tercera, del oficial de Bud a los padres de éste; y la cuarta, de Tommy, transformado en soldado. Mientras que el primero combate en las junglas del sudeste asiático para garantizar la democracia, el segundo, caracterizado con barba, protesta contra la guerra en la universidad. Sin embargo, afligido por la muerte de su hermano, completa su transformación en recluta durante la última carta ${ }^{16}$.

16. Perone, James E. (2001). Songs of the Vietnam Conflict, pp. 96-97, Westport: Greenwood Press. 


\subsection{La guerra en casa: el retrato de la anti-América}

La dificultad para sostener una guerra en dos frentes es un principio de poliorcética generalmente aceptado y la guerra de Vietnam no fue una excepción, si bien uno de esos frentes, el doméstico, era una contienda metafórica entre quienes apoyaban y quienes rechazaban el papel militar norteamericano en el sudeste asiático.

Después de una década en la que la lucha por los derechos civiles había copado la atención de los estadounidenses, las leyes promulgadas en 1964 y 1965 pusieron fin a la segregación racial de iure. Al mismo tiempo, la creciente intervención militar en las junglas de la antigua colonia de Indochina fue acaparando el interés de los estadounidenses, fragmentando su opinión pública. En mayo de 1965, la guerra de Vietnam era el mayor problema del país. Un año después, un $55 \%$ de la opinión pública estadounidense así lo veía y un magro, pero significativo 35 $\%$, apreciaba en la escalada militar un error ${ }^{17}$. Quienes se oponían al conflicto, no tardaron en forjar agrupaciones de estudiantes y ex combatientes con las que canalizaban su rechazo y mostraban su vigor social. No era extraño, por lo demás, ver entre los manifestantes a hippies, que expresaban su disconformidad con los cánones políticos y sociales establecidos. Entendiendo la juventud como una fase de experimentación más que como una de preparación, los hippies desafiaban a las estructuras de organización social y política tradicionales -familia, Iglesia, gobierno - a través de una novedosa estética y hábitos que incluían el consumo de drogas o el desahogo sexual. Todas estas conductas no pasarían por alto y conformarían la munición de las diatribas con las que el movimiento probélico apuntaba a los detractores de la guerra, caricaturizándolos como veremos a continuación.

El movimiento probélico, por su parte, continuaba dando síntomas de vitalidad. La manifestación de Nueva York en 1965 le permitió sacar músculo y durante los años siguientes, se llevaron a cabo pequeñas pero continuas manifestaciones de los jóvenes conservadores como, por ejemplo, los desfiles de apoyo de 1967 y 1969. En cuanto a los dos grandes partidos, ambos afrontaban la evolución de la contienda de manera diferente. Con L. B. Johnson empantanado en el conflicto, no pocos demócratas se distanciaban de la intervención, caso de Eugene McCarthy, George McGovern o R. F. Kennedy. Al mismo tiempo, el Partido Republicano guardaba un silencio cómplice después de la derrota electoral de 1964 que, traducido en apoyo tácito, aguardaba a que el desgaste del poder trajera mejores vientos de cara a la próxima cita con las urnas ${ }^{18}$.

17. Su, Yang y McAdam, D. (2002, October). «The War at home. Antiwar protests and Congressional Voting, 1965-1973», p. 698, American Sociological Review, Vol. 67, No 5, p. 698.

18. Scanlon, Sandra (2013). The pro-war movement. Domestic support for the Vietnam war and the making of Modern American conservatism, pp. 43-44, Amherst: University of Massachusetts Press. 
Ahora bien, ¿qué visión tenían los halcones de quienes rechazaban la guerra? Si ésta se llevaba a cabo en aras de proteger las fronteras de libertad y democracia que Estados Unidos representaba frente al totalitarismo soviético, cualquier actividad destinada a criticar el conflicto suponía un delito de lesa patria. El incremento de tensión entre detractores y defensores de la guerra quedó reflejado en las composiciones musicales del momento. En ellas, los cantautores, además de ensalzar el valor de los soldados norteamericanos, mostraban no tanto su apoyo al conflicto como su rechazo a las protestas que inundaban el país, etiquetando a los manifestantes a través de estereotipos como comunistas, faltos de higiene, antipatriotas y perturbadores del orden público. Entendían que, un país dividido en sus entrañas, no podía cumplir con su cometido y quienes lo ponían en riesgo eran, ergo, enemigos. Algunos cantautores como Kris Kristofferson o Tom T. Hall llegaron a puntualizar, con mayor o menor convencimiento, que sus canciones apuntaban más hacia los manifestantes pacifistas que a favorecer la política exterior estadounidense. Otros como como el conocido «Playboy de Tennesse», Eddy Arnold (Tennessee, 1918), se posicionaban abiertamente a favor del orden socia $^{19}$. Por consiguiente y como señala Bill C. Malone, eran «protestas contra quienes protestan $»^{20}$.

La ya aludida «What We' re Fighting for» (1965) escrita por Tom T. Hall e interpretada por Dave Dudley ya plantea este dilema en el que algunos cantantes country se movían. Bajo el formato de una carta escrita por un recluta enterado de las protestas que emanaban en las ciudades estadounidenses, el autor pedía a su madre que, aunque a las tropas destinadas no necesariamente les gustara la guerra, luchaban por las libertades de los survietnamitas en tanto que, si el comunismo avanzaba en la región, pronto les afectaría a los propios estadounidenses ${ }^{21}$. Por otra parte, esta obra también introduce un nuevo concepto en forma de yuxtaposición entre el «nosotros» o militares y el «ellos» o civiles que protestan, con lo que se diferencia abiertamente entre dos tipos de estadounidenses:

There's not a soldier in this foreign land who likes this war

Oh Mama tell them what we're fighting for

Tell Them that we're fighting for the old Red White and Blue

19. Streissguth, Michael (2009). Eddy Arnold: Pioneer of the Nashville sound, pp. 229-230, Jackson: University Press of Mississippi; Cobb, James C (1982). «From Muskogee to Luckenbach»: Country Music and the South-ernization of America», The Journal of Popular Culture, Vol. 16, No 3, pp. 83.

20. Malone, Bill. C. y Laird, Tracey E. W. (2018). Country Music USA, pp. 375-376, Austin: University of Texas Press.

21. Perone, James E. (2001). Songs of the Vietnam Conflict, pp. 80-81, Westport: Greenwood Press. 
Poco después, Ernest Tubbs colocaba a los hippies en la diana a través de «It's America (Love it or leave it!)» (1965). El carácter probélico de la canción queda circunscrito únicamente al título y estribillo de aquélla, ya que Tubbs eligió para él un lema del movimiento favorable al conflicto con el que se invitaba a los detractores a apoyarlo, o a abandonar el país en caso de no hacerlo. Por lo demás, la canción irradia una oposición frontal a la corriente antibélica, entendida como un grupo de agitadores que, a través del desorden público y el rechazo al alistamiento, amenazan los valores y creencias en los que han crecido cantautores como Tubbs, tales como el respeto a la bandera:

Well I'm gettin' mighty tired of seein' hippies runnin' wild

And burnin' down the schools and steppin' on the flag

Things are gettin' out of hand when you read about man

Who'll burn his draft car then hang around the pool room and brag

Some folks think it's okay, but I wasn't raised that way

And I won't be satisfied 'til I've had my say

A mediados de 1966, Johnny Sea (Mississippi, 1940) grabó «Day for Decision». Escrita por el presentador de telediarios Allen Peltier y arreglada musicalmente por Ernie Freeman, la canción se desarrolla con un marcado estilo recitativo. En un principio, con una apocalíptica descripción del comunismo, acompañada del uso de escalas pentatónicas que simulan música asiática, identificando nítidamente Vietnam, comunismo y las penurias que genera, para a continuación, incluir un diagnóstico para las dificultades estadounidenses en superar el conflicto: una enfermedad en forma de falta de patriotismo que amenaza el estilo de vida americano y que corroe las calles de San Francisco, San Luis o Chicago. Y es que una segunda parte de la obra exalta los valores de la sociedad estadounidense en un estilo totalmente contrapuesto al inicio de la canción: una marcha militar que rebosa optimismo para exponer qué valores de libertad que EE.UU. irradia. La guerra es, además, una contraposición entre la cultura cristiana y la barbarie asiática comunista, con lo que el autor soslaya el carácter multirreligioso de la sociedad y ejército estadounidenses, así como la existencia de cristianos entre los propios vietnamitas ${ }^{22}$.

El actor Kris Kristofferson (Texas, 1936) expuso su visión particular sobre el conflicto en «Vietnam Blues» (1965), alegato militarista y en el que Kristofferson, narraba el impacto que le provocó un incidente durante un viaje a Washington D.C. en el que varios manifestantes le pidieron firmar un documento de apoyo a Ho Chi Minh. La tonada fue grabada en 1966 por Dave Dudley y Kristofferson,

22. Perone, James E. (2001). Songs of the Vietnam Conflict, pp. 87-88, Westport: Greenwood Press. 
en lugar de colocarse a sí mismo en la canción, escribe la historia de un soldado de permiso en la capital estadounidense que se encuentra con varios manifestantes contrarios al conflicto, los cuales son descritos a través de estereotipos como largas melenas, ropajes extraños y barbas. A pesar de estas convicciones iniciales sobre el conflicto, Kristofferson no tardaría en experimentar un cambio de $180^{\circ}$ en su opinión al respecto ${ }^{23}$. En la misma opinión se manifestó Marty Robbins (Arizona, 1925) en "Ain't I right» (1966). En ella, aquellos que se mostraban contrarios a la guerra eran retratados como «bearded, bathless bunch» («grupo de barbudos y sucios»). El propio Robbins etiquetaba sus protestas como un «beso a los comunistas». Robbins y sus convicciones anticomunistas están fuera de toda duda. Identificado como un republicano conservador, no dudó en apoyar abiertamente la campaña presidencial de Barry Goldwate ${ }^{24} \mathrm{o}$ del ex gobernador segregacionista de Alabama y candidato a la Casa Blanca George Wallace cuatro años más tarde.

También en 1966 Pat Boone compuso «Wish You Were here, Buddy», obra sobre la que existe un curioso debate historiográfico ya que no existe un acuerdo nítido sobre la temática de la misma y que resultó menos exitosa que otras melodías previas del cantante floridano. Mientras que algunos investigadores observan en la obra una muestra de apoyo a los combatientes en Vietnam, otros sugieren un desprecio a los manifestantes antibélicos ${ }^{25}$. En cualquier caso, resultan innegables las crueles referencias al movimiento antibelicista, ya que Pat Boone toma el formato de una carta escrita por un soldado que combate en Vietnam a un compañero de instituto, al que caracteriza, de manera literal, como un hombre de las cavernas con greñas y barba. En ella, además, le invitaba a combatir, ocasión que aprovecha para poner en duda su coraje. A la hora de realizar este cuestionamiento, Boone le compara con Cassius Clay, a la sazón ya Muhammad Ali, boxeador célebre por agotar a sus rivales mediante ágiles evasivas, pero quien también se había negado a ser reclutado para la guerra de Vietnam. No sería la única vez que se expresaban este tipo de ideas, ya que Harlan Howard y Stonewall Jackson emplearon una argumentación similar en la ya descrita «The Minute Men» (1966). En esta obra, los autores señalan a los manifestantes pacifistas como lacayos comunistas y cobardes traidores por su negativa a luchar en el conflicto.

Sin embargo, el retrato más punzante del movimiento antibelicista no llega hasta 1969, fecha de edición de «Okie from Muskogee». Obra de Merle Haggard (California, 1937), se trata probablemente de la más célebre de entre todas las

23. Hurd, Mary G. (2015). Kris Kristofferson, p. 73-74, Londres: Rowman \& Littlefield.

24. Diekman, Diane (2012). The life of Marty Robbins, p. 99, Chicago: University of Illinois Press. Press.

25. Perone, James E. (2001). Songs of the Vietnam Conflict, p. 90, Westport: Greenwood 
canciones que han criticado el movimiento pacifista. El momento de composición de la obra no pudo ser más oportuno, ya que después de los asesinatos de Robert F. Kennedy y sobre todo de Martin Luther King en 1968, los disturbios se multiplicaron por toda la geografía estadounidense en ciudades como Chicago, Detroit, Kansas City, Washington o Baltimore, generando la consiguiente alarma social.

Merle Haggard procedía de una familia rural de Oklahoma que había migrado a California durante la Gran Depresión. Allí había crecido en un entorno humilde en la ciudad californiana de Bakersfield, lo que, al tiempo que se iniciaba como cantante de música country, le llevó a cometer varios delitos que le condujeron a prisión en 1957. Al salir de ésta, reinició su carrera musical hasta grabar una decena de álbumes y cosechar varios premios individuales. Simultáneamente, la escalada bélica en el sudeste asiático crecía y a finales de la década, incluso ampliaba su radio de acción, entrando en países vecinos como Cambodia. Ello desencadenaba protestas aún más furibundas por parte del movimiento antibelicista, lo cual no pasó inadvertido para quienes apoyaban el conflicto o quienes miraban con recelo estas manifestaciones, ya que debilitaban el espíritu bélico de la nación, pero sobre todo, ponían en peligro el orden social y la propiedad privada. Fue en este contexto en el que Haggard compuso "Okie from Muskogee», concebida posiblemente durante un viaje entre Arkansas y Oklahoma y grabada junto al grupo The Strangers durante el verano de $1969^{26}$.

La canción representa el fervor anticomunista de la población blanca rural de los estados meridionales y del Medio Oeste, así como el orgullo hacia sus tradiciones: «I'm proud to be an Okie from Muskogee» indica una de las estrofas. Uno de estos estados es Oklahoma, en el que hundía sus raíces la familia de Haggard. Su gentilicio es okie y cercana a la frontera con Arkansas, su undécima ciudad es Muskogee. Entre ambas palabras, dan nombre a una composición con la que Haggard rechaza el estilo de vida del movimiento hippie sin disimulo, al identificarlo con el consumo de drogas, el desorden y el rechazo al alistamiento, reduciendo y vulgarizando a todo opositor a la guerra con características con las que identifica al movimiento hippie:

We don't smoke marijuana in Muskogee

We don't take our trips on LSD

We don't burn our draft cards down on Main Street

We like livin' right, and bein' free

Publicada en septiembre de 1969 , la canción fue aceptada de inmediato por la población conservadora y blanca de áreas rurales de Estados Unidos,

26. Cantwell, David (2013). Merle Haggard: the running kid, pp. 150-152, Austin: University of Texas Press. 
potencialmente conservadoras. Durante su estreno en ante la guarnición de Fort Bragg (Carolina del Norte), Haggard recibió un baño de masas por parte de la soldadesca entusiasta ${ }^{27}$. No fue el único síntoma de éxito de la tonada, ya que varios dirigentes políticos mostraron su simpatía al respecto. Por ejemplo, el recién electo presidente Richard Nixon lo recibió como un espaldarazo a su política en el sudeste asiático y agradeció la composición en una carta a Haggard. La Country Music Association la galardonó como la mejor canción country del año $1969^{28}$, abriendo las puertas al éxito al cantautor californiano, que pronto vio vendidas 885.000 copias del álbum ${ }^{29}$. Aunque cabe interpretar la letra de la canción como una parodia o incluso una broma, más adelante el propio Haggard disiparía dudas al respecto al señalar en varias entrevistas cuánto le enervaba la falta de decoro físico de los hippies, así como su taxativo rechazo a la visión del mundo que aquéllos profesaban ${ }^{30}$.

La canción no fue la última contribución de Haggard sobre el debate bélico. Tan solo unos meses después del éxito de «Okie from Muskogee», el cantante de Bakersville escribió «The Fightin's Side of Me». Publicada en diciembre de 1969, Haggard volvió a inmiscuir sus emociones personales para mostrar su rechazo al movimiento hippie, al cual, siguiendo el lema probélico del momento, invitaba a abandonar el país — «If You Don't Love it, Leave it» - . De este modo, Haggard consagraba el monopolio del ser estadounidense para aquéllos que se mostraban a favor del conflicto y no amenazaban con subvertir el orden doméstico.

\subsection{La universidad, un antro progresista}

La oposición al conflicto encontró entre la juventud estadounidense un caldo de cultivo notable. El lugar de reunión quedó emplazado en las universidades que, imbuidas de retórica antibelicista, vieron la gestación de diversos grupos de oposición a la guerra. Reflejo de esta tendencia fue la proliferación de asociaciones que desafiaban el orden establecido en una doble vertiente. Por un lado, arremetían contra la segregación racial como estructuración social injusta. Por otro, criticaban la participación militar en el sudeste asiático como pilar de la política exterior del país. No eran pocas las universidades que reclamaban una mayor libertad de

27. La Chapelle, Peter (2007). Proud to be an Okie. Cultural politics, country music, and migration to Southern California, pp. 180, Berkeley: University of California Press.

28. Hillstrom, Kevin y Hillstrom, Laurie Collier (1998). The Vietnam experience. A concise encyclopedia of American Literature, Songs and Films, pp. 219-220, Westport: Greenwood Press.

29. La Chapelle, Peter (2007). Proud to be an Okie. Cultural politics, country music, and migration to Southern California, p. 181, Berkeley: University of California Press.

30. Cantwell, David (2013). Merle Haggard: the running kid, pp. 154-155, Austin: University of Texas Press. 
expresión. Del mismo modo, centros como las de Berkeley, Michigan, Kent State o Wisconsin acogieron protestas de manera asidua. Es así como surgió, por ejemplo, el Movimiento por la Libre Expresión (Freedom Speech Movement, FSM) que, con base en la universidad californiana de Berkeley, pronto tendió puentes con el movimiento de pro-derechos civiles y enarboló la bandera antibélica. Los Estudiantes por una Sociedad Democrática (Students for a Democratic Society, SDS) tenían una base social más amplia, al incluir no sólo a estudiantes sino también a madres y religiosos. El Comité Coordinador Estudiantil No Violento (Committee for NonViolent Action, CNVA) se centraba en la crítica al programa de rearme nuclear y criticaba la segregación racial... La lista de agrupaciones es ingente, pero no constituyen objeto de estudio de este trabajo. Todas ellas ejercían una labor didáctica a través de seminarios y conferencias a lo largo y ancho del país con el objetivo de educar a los estudiantes acerca de la implicación estadounidense en la contienda. Los seminarios sobre la guerra, entonces llamados teach-in, eran considerados no sólo antipatrióticos, sino que también rozaban la traición para quienes apoyaban la escalada militar ${ }^{31}$. Estas manifestaciones antibélicas solían estar, por lo demás, nutridas del movimiento hippie que, deseoso de quebrar las normas sociopolíticas y morales de cualquier estructura establecida, habían hecho del antibelicismo su estandarte y comenzaban a hacerse sentir en las ciudades norteamericanas.

De este modo, el ambiente antibelicista inundó los campus universitarios estadounidenses. La primera protesta sincronizada, habida lugar en más de una docena de ciudades en diciembre de 1964, dio paso a un rosario de manifestaciones durante los años siguientes: Washington en 1965, Nueva York en 1966, Washington, Nueva York y San Francisco en 1967... Desde 1969, la guerra era cada vez más impopular y las protestas universitarias resultaban ensordecedoras ${ }^{32}$, con lo que, en estas mismas fechas, las tornas de la opinión pública se habían invertido y un $55 \%$ de los estadounidenses rechazaban el conflicto ${ }^{33}$. Observando estos datos, resulta lógico que quienes se mostraban favorables a la intervención militar en Vietnam desconfiaran de las universidades, a las cuales observaban como centros de adoctrinamiento y subversión de dudosa lealtad.

En consecuencia, no es de extrañar que las universidades estuvieran en el ojo del huracán para los compositores de música country. Autry Inman (Alabama,

31. Scanlon, Sandra (2013). The pro-war movement. Domestic support for the Vietnam war and the making of Modern American conservatism, pp. 62-63, Amherst: University of Massachusetts Press.

32. Schreiber, E. M. (1973, September). «Opposition to the Vietnam war among American University Students and Faculty», The British Journal of Sociology, Vol. 24, No 3, pp. 289-291.

33. Su, Yang y McAdam, Doug (2002). «The War at home. Antiwar protests and Congressional Voting, 1965-1973», p. 698, American Sociological Review, Vol. 67, No 5, p. 699. 
1929) en «The Ballad of the two Brothers» (1968) contrapone a dos hermanos que combaten en Vietnam - Bud - y en la universidad - Tommy - por motivos diametralmente opuestos. Evidentemente, Tommy es caricaturizado como un joven problemático, voluble y barbudo que, además, exprime económicamente a sus padres. Se trata, por qué no decirlo, de un parásito que no hace sino contribuir a la derrota moral y política de la nación, idea que recogerá el conservadurismo reaganiano una década después. Al ser las universidades uno de los epicentros de las protestas antibélicas, el profesorado queda caracterizado como un peligroso progresista que utiliza su posición para lavar el cerebro a sus alumnos y utilizarlos como peones del comunismo:

Our economics professor assured us

That people get along

Just as well under communism

As they do under

Any other form of government

La desconfianza en las universidades y su personal docente constituye una idea notablemente extendida entre quienes denostaban al movimiento antibélico. En «Mister Professor» (1971), Harlan Howard carga las tintas contra aquellos maestros que inducen a sus pupilos hacia el ateísmo, la resistencia al alistamiento $\mathrm{y}$ al desorden, lo que induce a pensar en las universidades como verdadero semillero antibélico en la cosmovisión country, obviando otras fases de desarrollo del manifestante y generalizando la sospecha sobre todo el cuerpo docente. Si la figura del profesor quedaba bajo cuestión al ser considerado elemento instigador, no menos importante es la otra cara de la moneda, esto es, la ausencia de una referencia moral para el alumnado, tal y como se observa en «Where Have all the Heroes Gone?» (1970) ${ }^{34}$. En ella, Bill Anderson (Carolina del Sur, 1937) constata la falta de referentes morales para la juventud estadounidense ${ }^{35}$, critica a quienes rechazan el alistamiento e incluso arremete contra Joan Baez, aunque sin decirlo explícitamente: la cantante neoyorkina, que desde 1964 había rechazado pagar aquellos impuestos que estuvieran destinados al incremento del gasto militar, quedaba ubicada entre los traidores de la siguiente manera:

34. Perone, James E. (2001). Songs of the Vietnam Conflict, pp. 99-101, Westport: Greenwood Press.

35. Bill Anderson incluyó entre la lista de héroes a pioneros de la aviación como Charles Lindberg, actores como John Wayne, políticos como Dwight Eisenhower, Winston Churchill, J. F. Kennedy y Martin L. King. Precisamente ante la inclusión de estos dos últimos, varias estaciones de radio censuraron sus nombres durante la edición. Perone, James E. (2001). Songs of the Vietnam Conflict, p. 99, Westport: Greenwood Press. 
And a story of a folk singer who proudly claims

To be both a member of a party ailen

To our government and a nontax payin' citizen (...)

These young boys read with open eyes and open minds

And I thought to myself my God

Are these the people that these young boys look up to

Are these their idols, are these the heroes

Of the now generation?

\section{5. ¿Y los veteranos?}

Quienes participaron en la guerra de Vietnam desempeñaron un papel primordial no sólo como protagonistas combatientes, sino también a su regreso a Estados Unidos. Los reclutas se alistaban bajo la promesa de luchar por la libertad y la democracia en el sudeste asiático, elevado a la categoría de frontera nacional. Sin embargo, una vez cumplido su servicio y regresaban a Estados Unidos, los veteranos encontraban no sólo dificultades para adaptarse a la vida civil, sino también con que gran parte de la población les vilipendiaba y tildaba de criminales por su papel en el conflicto.

Y es que, hasta la fecha, los soldados estadounidenses habían tornado a su país victoriosos - sendas guerras mundiales - o en el peor de los casos, después de una paz incómoda - Corea-. En esta ocasión, los soldados regresaban del sudeste asiático derrotados. Debido a la impopularidad de la conflagración, el soldado estadounidense carecía de reconocimiento público, ya que la sociedad le observaba con una mezcla de indiferencia y hostilidad. Al mismo tiempo, la responsabilidad en el resultado de la guerra recaía sobre sus hombros. Mientras que los conservadores les achacaban la derrota, los progresistas les recriminaban haber participado en la lucha. Todo ello, unido a la falta de apoyo oficial, provocó que los veteranos se sintieran desamparados. Para salir de esta aflicción, no pocos veteranos unieron fuerzas en agrupaciones como la Vietnam Veterans Against the War (VVAW), fundada en 1967; los Veteranos contra el Fascismo (GI's Against Fascism) o el Movimiento por un Ejército Democrático, fundadas ambas dos años después.

No fue hasta la década de 1980 cuando se inició un reconocimiento gracias a la labor de diversas organizaciones de veteranos, pero también como resultado de la nueva retórica heroica que Ronald Reagan había implantado en la Casa Blanca $(1982)^{36}$.

36. Anderson, David L. (2002). The Columbia Guide to the Vietnam war, pp. 168-169, Nueva York: Columbia University Press. 
En lo que se refiere a aspectos musicales, los veteranos estuvieron no acapararon los focos de atención. Para quienes se mostraban críticos con la guerra, los veteranos no hicieron acto de presencia en sus canciones prácticamente hasta la década de 1980, caso de Billy Joel o Bruce Springsteen, autores de «Goodbye Saigon» (1982) $\mathrm{y}$ «Born in the USA» (1984) respectivamente. Por su parte, los apologetas del conflicto apreciaron en la figura del veterano como un elenco de valores a resaltar. A pesar de ello, la mayoría de compositores prefirieron un enfoque neutro sobre la figura del veterano. En lugar de reflejar el dolor, los traumas ocasionados por la guerra o las experiencias de combate, no pocos cantantes enfocaban el regreso a casa como una reunión con sus seres queridos. Por ejemplo, «Coming Home Soldier» (1967), coescrita por Bobby Vinton (Pensilvania, 1935) y Gene Allen (Indiana, 1928), describe la felicidad de un soldado que retorna a su amada después de haber combatido en un conflicto sin especificar. Algo más amargo, aunque no por ello partidista, es el enfoque del cantante country Mel Tillis (Florida, 1932). Tillis plasmó en «Ruby, Don't Take your Love to Town» (1967) la visión de un veterano que, al regresar paralítico al hogar, pide a su esposa que le ame por igual, tras lo cual, ella le abandona. La canción, como el propio Tillis indica en sus memorias, carece de cualquier crítica política o al movimiento antibélico ${ }^{37}$.

\section{6. ¿Fueron los cantantes country un grupo monolitico?}

Hasta el momento, el presente estudio se ha centrado en las preferencias temáticas de los compositores de música country a la hora de reflejar la realidad social que padecía Estados Unidos durante su participación en la Guerra de Vietnam. De ello, el lector pudiera extraer la idea de que el género country se posicionó de manera homogénea a favor de la intervención militar estadounidense en el sudeste asiático y en denostar a los detractores de aquélla. Esta afirmación debe ser puntualizada. Si bien es cierto que una amplia mayoría de los compositores de este género se posicionaron abiertamente a favor del conflicto por motivos ya explicados, no lo es menos que hubo excepciones notorias. Una de ellas fue Glen Campbell (Arkansas, 1936), quien en 1965 editó «Universal Soldier», obra compuesta por la cantante canadiense Buffy Sainte Marie un año antes. No están claras las razones por las que Campbell decidió interpretar esta canción. Si bien se trata de una obra marcadamente antibelicista y en consecuencia elevada a la categoría de himno por el movimiento pacifista, Campbell había realizado declaraciones en las que cuestionaba el valor de quienes no luchaban por su país. Sin embargo, quienes grababan una canción que no era propia, solían hacerlo en concordancia con las ideas que la pieza expresaba, en cuyo caso, si el cantante

37. Tillis, Mel (1984). Stutterin’ boy, pp. 65-67, New York: Rawson Associates. 
arkansés había editado esta canción, es porque estaba comprometido en mayor o menor medida con la causa ${ }^{38}$.

Dejando el interrogante que plantea Campbell a un lado, encontramos varias referencias notables dentro de la música country que no se posicionaron a favor de la guerra. En primer lugar, John Denver (Nuevo México, 1943), cuya oposición a la contienda le llevó a participar en abril de 1971 en las manifestaciones que tuvieron lugar en Washington DC y entonar en ella «Last Night I had the Strangest Dream», alegato antibelicista compuesto en 1950 por Ed McCurdy y versionada con éxito catorce años después por Pete Seeger. Curiosamente, Denver sería el primer estadounidense que cantaba en Vietnam desde el final del conflicto durante la gira que llevó en el país asiático en 1994.

En segundo lugar, para Johnny Cash (Arkansas, 1932), música, patria y guerra supusieron un dilema moral a causa de sus convicciones referentes a justicia social y patriotismo, exhibiendo una confusa ambigüedad ${ }^{39}$ destinada quizás a mantener en vilo a la audiencia ${ }^{40}$. Y es que Cash admiraba a los soldados que luchaban por su país en Vietnam, pero al mismo tiempo simpatizaba con los manifestantes antibélicos. Valgan para ejemplificar su funambulismo moral dos anécdotas. Durante un concierto en el Madison Square Garden en 1969 recordó una entrevista con un periodista después de regresar de visitar a los combatientes en el frente:

Periodista: «That (visitar a los soldados en el frente) makes you a hawk, doesn't it?»

Cash: «No, no, that don't make me a hawk. But I said if you watch the helicopters bring in the wounded boys, and then you go into the wards and sing for them and try and do your best to cheer them up so they can get back home, it might make you a dove with claws» ${ }^{41}$.

Acto seguido, Cash interpretó «Last Night I Had the strangest Dream». En segundo lugar, durante una visita a la Casa Blanca en 1971, el presidente Nixon le pidió que interpretara «Okie from Muskogee». Sin embargo, ya fuera por desconocimiento y falta de práctica como señala el propio Cash en su autobiografía, o por simpatía con los manifestantes, Cash se negó. La disyuntiva que se abría ante Cash le hacía elegir entre su patriotismo o justicia social, conceptos

38. Perone, James E. (2001). Songs of the Vietnam Conflict, pp. 31-33, Westport: Greenwood Press.

39. Silverman, Jonathan (2010). Johnny Cash and American Culture. Nine choices, pp. 131-132, Boston: University of Massachusetts Press.

40. Edwards, Leigh H. (2009). Johnny Cash and the paradox of American identity, pp. 131-132, Bloomington: Indiana University Press.

41. "Actuación de Johnny Cash en el Madison Square Garden, 5 de diciembre de 1969.» [última consulta, 17 de agosto de 2018 en https://www.youtube.com/watch?v=cZwTfPKW6v0]. 
arraigados en su persona. Finalmente, Cash optó por una curiosa combinación de ambas. Durante la campaña electoral que tendría lugar el año siguiente, el cantante apoyó la reelección de Nixon como presidente ${ }^{42}$. De este modo, la aceptación de la autoridad presidencial suponía la capitulación ante el estado como garante de los derechos individuales ${ }^{43}$.

Para otros artistas, caso de Ray Stevens (Georgia, 1939), la guerra y las protestas consiguientes fueron motivo de hastío y por ello alzan la voz por una tercera vía. En «America, Communicate with Me», el autor se ubica equidistante entre los manifestantes pacifistas y quienes jalean el lema probélico «America, Love it or Leave it», para a continuación, apostar por una mejor comunicación entre sus conciudadanos para como posible solución. Ésta sería posible, en su opinión, si los líderes capaces no hubieran sido asesinados por las balas, en clara alusión a Robert F. Kennedy y Martin Luther King ${ }^{44}$.

Por último, si Nashville conformó un establishment musical conservador aliado tanto con el Partido Republicano como con los demócratas segregacionistas encabezados por George Wallace, la alternativa musical se ubicó en Austin (Texas), donde al calor de la universidad, la obra de Willie Nelson y los movimientos estudiantiles ya mencionados que en ella se desarrollaban, floreció una rama de música country progresista que distendió el agresivo discurso pronunciado desde Tennessee ${ }^{45}$.

\section{CONCLUSIONES}

A lo largo de este artículo hemos trazado varios pilares para sostener nuestra hipótesis. En primer lugar, las reformas sociales deseadas por el gobierno demócrata de J. F. Kennedy y llevadas a cabo por Lyndon B. Johnson destinadas a germinar la Gran Sociedad, despertaron la hostilidad de algunas regiones del país. Como consecuencia, se gestó una reacción conservadora encabezada por candidatos a la presidencia por parte del Partido Republicano como Barry Goldwater, Richard Nixon y Ronald Reagan o por parte del propio Partido Demócrata en la figura de George Wallace y que abogaban por un menor control federal en los asuntos de los estados. Además, abogaban por un mayor rigor moral, ya que entendían

42. Streissguth, Michael (2006). Johnny Cash. The biography, p. 186, Cambridge (MA): Da Capo Press.

43. Edwards, Leigh H. (2009). Johnny Cash and the paradox of American identity, pp. 56-58, Bloomington: Indiana University Press.

44. Perone, James E. (2001). Songs of the Vietnam Conflict, pp. 99-100, Westport: Greenwood Press.

45. Stimeling, Travis D. (2011). Cosmic cowboys and New Hicks. The countercultural sounds of Austin's progressive country music scene, pp. 2-5, New York: Oxford University Press. 
que dichos programas sociales fomentaban el parasitismo y desmotivaban a la juventud, crítica con las tradiciones que enmarcaban la vida cotidiana y el papel de Estados Unidos como garante de estas esencias.

Esta generación encontró en la canción folk una forma de manifestación apropiada y sensible a unas inquietudes progresistas que desafiaban el orden social establecido y la política activa internacional estadounidense. En cuanto al movimiento conservador, éste quedó especialmente arraigado en dos ámbitos. Por un lado, las regiones meridionales del país, que veían su modo de vida en peligro. Por otro lado, también entre clases medias urbanas, distanciadas del desorden generado por las diferentes protestas. Curiosamente, muchas de estas gentes descendían de la migración interior desde los estados meridionales hacia lugares como la alta California, acaecida durante la década de 1940. Merle Haggad, por consiguiente, constituye un nítido ejemplo de cómo la música country fue capaz de superar las fronteras del cinturón bíblico sureño.

Especialmente arraigada en los estados del sur y del Medio Oeste, pero también exportada de manera paulatina a otras regiones, la música country ejerció desde la década de 1950 como vehículo de expresión de los atributos que, a su juicio, vertebraban la sociedad estadounidense: libertad, democracia, cristianismo y orden social. En pleno estallido de la Guerra Fría, ello llevó a varios cantautores mostrar un rechazo visceral a la Unión Soviética y a la expansión del comunismo. Esta actitud conducía directamente a apoyar cualquier política de contención por parte de Estados Unidos, dando credibilidad a la teoría del dominó por la que el sudeste asiático se convertía en frontera norteamericana de manera automática. Garante de la libertad y de la democracia como parte de su existencia, Estados Unidos pasaba a ser una fuerza policial allá donde se sintiera la amenaza.

A partir de 1965, la creación de música country se multiplicó exponencialmente por todo el país gracias a la diseminación de población sureña durante las décadas previas y la producción de música favorable a la intervención en Vietnam no fue una excepción. El country consiguió ensanchar su base social por todo el país durante las décadas de 1960 y 1970 y no resultaba extraño producirlo en los Rust Belt y Sun Belt, centros receptores de aquella población. Después de las elecciones de 1968, presidentes como Nixon se preocuparon de que el Sur fuera aceptado con sus particularidades y el country era una de ellas ${ }^{46}$. Los músicos que defendían la participación en Vietnam lo hacían bajo unas premisas evidentes en sus composiciones. En primer lugar, justificaban la intervención militar y apoyaban el papel de Estados Unidos como garante de un cordón sanitario y defensor de la

46. Cobb, James C. (1982). «From Muskogee to Luckenbach»: Country Music and the South-ernization of America», The Journal of Popular Culture, Vol. 16, No 3, pp. 83-84. 
democracia ${ }^{47}$. Así queda constatado en varias tonadas escritas e interpretadas por Tom T. Hall, Johnnie Wright y Dave Dudley. En esta apología, resulta paradójico que, si bien se incide en la libertad estadounidense, nunca son mencionados los derechos del pueblo vietnamita como pueblo independiente empantanado en una larga lucha colonial durante dos décadas y que soportaba un régimen dictatorial tras otro patrocinado por Estados Unidos. En segundo lugar, las letras generalmente omiten acontecimientos y personajes concretos y en su lugar referencian aspectos heroicos y el sacrificio de las tropas estadounidenses. Para ello, se elige con cierta asiduidad el formato de plegarias - «God please Protect America» - y especialmente de cartas escritas desde el frente por los soldados a sus familias para que, de este modo, pudieran ejercer como ejemplo. Existen también algunas obras en forma de desengaños amorosos y traiciones al soldado que combate. Ello bien podría ser considerado como una referencia a la oposición al conflicto que por el entonces germinaba dentro del país, pero no contamos con información suficiente que conduzca a pensar en una relación directa entre ambas ideas.

Ello nos lleva a una tercera consideración. La necesidad de crear una narrativa heroica se entiende a partir del surgimiento de un potente movimiento de oposición a la guerra, caracterizado en manifestaciones y resistencia al reclutamiento. A ojos del movimiento probélico y de los cantantes country, en ellas confluían quienes se oponían al papel policial de EE.UU., sino también opositores a la segregación racial e integrantes del movimiento hippie, declarados pacifistas. Este movimiento, entendiendo la juventud como una fase de experimentación, transgredía las normas sociales a través del consumo de drogas y la experimentación con sus cuerpos y mostraban su disconformidad a través de protestas. Especialmente desde el turbulento 1968, las melodías country no tardaron en extender estos conceptos hasta convertirlos en imágenes caricaturescas faltas de higiene y drogadictas, cuyo máximo exponente es «Okie from Muskogee». Eran protestas contra las protestas. Desde esta perspectiva, el movimiento hippie y los pacifistas quedan elevados a la categoría de perturbadores de la paz social. Sus integrantes son retratados tanto como cobardes como una quinta columna comunista, lo que retroalimenta la necesidad de luchar contra el comunismo en las junglas del sudeste asiático. Curiosamente, esta narrativa será recogida años después por el conservadurismo reaganiano, que no dudará en culpar del resultado de la intervención militar a los disidentes internos, ya retratados como chupópteros con las greñas de Tarzán, andares de Jane y el olor de Cheetah ${ }^{48}$. En la diana de estas críticas quedó también

47. Hillstrom, Kevin y Hillstrom, Laurie Collier (1998). The Vietnam experience. A concise encyclopedia of American Literature, Songs and Films, p. 217, Westport: Greenwood Press.

48. «Ronald Reagan, the enemy of hippies, love and fun, on hippies», [última consulta el 17 de agosto de 2018 https://www.youtube.com/watch?v=GnHmhAL9hm0]. 

MOVIMIENTO PROBÉLICO EN ESTADOS UNIDOS

situada la universidad estadounidense, sobre la que existen referencias acerca de un comportamiento que en su conjunto queda definido como desleal y antipatriótico. Esta actitud hostil hacia el movimiento antibélico en las canciones se mantuvo hasta el final del conflicto, momento en el que los cantautores country cesaron en sus diatribas hacia los manifestantes ${ }^{49}$.

El género country constituyó un bloque relativamente favorable a la participación militar estadounidense. Conviene realizar algunas matizaciones al respecto. En primer lugar, la ciudad de Austin se erigió como baluarte progresista del género al calor de la universidad de la población tejana. En segundo lugar, existen excepciones significativas en su posicionamiento hacia el conflicto, caso de John Denver y Glen Campbell. Otros como Johnny Cash, Tom T. Hall o Kris Kristofferson hacían malabarismos morales. El primero en apoyo de combatientes y manifestantes por igual, los dos últimos rechazando la violencia militar y al movimiento antibélico. Por lo demás, el cantautor country un es activista político de manera tácita. Al igual que muchos cantantes que se mostraron contrarios al conflicto como Bob Dylan o Joan Baez participaban en marchas o conciertos sobre la causa, la presencia de los halcones en este tipo de eventos es evidente, aunque no palmaria. La participación de Chet Atkins, Skeeter Davis y Eddy Arnold en 1965 en la Universidad de Vanderbilt o de Merle Haggard ante la soldadesca en 1969 son evidentes, pero tampoco deben ser considerados como una norma. Del mismo modo, algunos cantautores prestaron su imagen a campañas políticas. El gremio country de Nashville en general y Marty Robbins en particular se posicionaron a favor de George Wallace en $1968^{50}$, Eddy Arnold hizo lo propio con Richard Nixon en $1968^{51}$ y Johnny Cash apoyó al propio Nixon cuatro años después. Todos ellos constituyen ejemplos que contribuyeron a incrementar la imagen del country como música de raigambre conservadora, aunque ello no suponga un hábito generalizado. En todo caso, los músicos country parecían mostrar más su oposición a la inestabilidad social que apoyar a la propia guerra en sí.

No resta a este estudio sino realizar una breve puntualización. Debido a la limitación de espacio con la que contamos, nos hemos visto obligados a no incluir otras formas y géneros de expresión de quienes apoyaban la intervención estadounidense en Vietnam. Cabe citar, por ejemplo, «The ballad of the Green Berets» (1966), «The Dawn of correction» (1965) como respuesta al tema de Barry McGuire o aquellas canciones con significado patriótico, alineadas con el

49. Malone, Bill. C. y Laird, Tracey E. W. (2018). Country Music USA, p. 377, Austin: University of Texas Press.

50. Stimeling, Travis D. (2011). Cosmic cowboys and New Hicks. The countercultural sounds of Austin's progressive country music scene, p. 65, New York: Oxford University Press.

51. Streissguth, Michael (2009). Eddy Arnold: Pioneer of the Nashoille sound, 229-230, Jackson: University Press of Mississippi. 
JUAN ANDRÉS GARCÍA MARTÍN

EL COUNTRY SE VA A LA GUERRA: EL APOYO A LA GUERRA DE VIETNAM Y EXPRESIÓN DEL MOVIMIENTO PROBÉLICO EN ESTADOS UNIDOS

movimiento probélico. Su ausencia solo puede ser completada en futuros estudios sobre la cuestión.

\section{REFERENCIAS BIBLIOGRÁFICAS}

Anderson, David L. (2002). The Columbia Guide to the Vietnam war. Nueva York: Columbia University Press.

Cantwell, David (2013). Merle Haggard: the running kid. Austin: University of Texas Press.

Cobb, James C (1982). «From Muskogee to Luckenbach»: Country Music and the Southernization of America», The Journal of Popular Culture, Vol. 16, No 3, pp. 81-91.

De Iturrate Cárdenes, Luis Fernando (2003). Grandes músicos para una guerra. Santa Cruz de Tenerife: Color-Relax.

Diekman, Diane (2012). The life of Marty Robbins. Chicago: University of Illinois Press.

Edwards, Leigh H. (2009). Johnny Cash and the paradox of American identity. Bloomington: Indiana University Press.

Fernández Ferrer, Antonio (2007). La canción folk norteamericana. Granada: Universidad de Granada.

Goldwater, Barry (1961). The conscience of a conservative. New York: MacFadden-Bartell Co.

Gritzner, Charles F. (1978). «Country Music: a reflection of popular culture», The Journal of Popular Culture, Vol. 11, No 4, pp. 857-864.

Haggard, Merle (1999). Merle Haggard's. My house of memories. New York: Harper Collins.

Hillstrom, Kevin y Hillstrom, Laurie Collier (1998). The Vietnam experience. A concise encyclopedia of American Literature, Songs and Films. Westport: Greenwood Press.

Hinton, Brian (2000). Country Roads. How Country Came To Nashville. London: Sanctuary Publishing.

Hurd, Mary G. (2015). Kris Kristofferson. Londres: Rowman \& Littlefield.

Jones, Maldwyn A. (1995). Historia de Estados Unidos. Madrid: Cátedra.

Kingsbury, Paul (1998). The Encyclopedia of country music. The ultimate guide to music. New York: Oxford University Press.

La Chapelle, Peter (2007). Proud to be an Okie. Cultural politics, country music, and migration to Southern California. Berkeley: University of California Press.

Larkin, Colin (2002). The Virgin Encyclopedia of the Sixties music. London: Virgin.

Lynn, Loretta (1996). Loretta Lynn: coal's miner daughter. New York: Da Capo Press.

Malone, Bill. C. y Laird, Tracey E. W. (2018). Country Music USA. Austin: University of Texas Press.

$\mathrm{Su}$, Yang y McAdam, D. (2002). «The War at home. Antiwar protests and Congressional Voting, 1965-1973», American Sociological Review, Vol. 67, № 5., pp. 696-721.

O'Nan, Stewart (1998). The Vietnam reader: the definitive collection of American fiction and nonfiction on the war. New York: Anchor Books.

Perone, James E. (2001). Songs of the Vietnam Conflict. Westport: Greenwood Press. 
Scanlon, Sandra (2013). The pro-war movement. Domestic support for the Vietnam war and the making of Modern American conservatism. Amherst: University of Massachusetts Press.

Schreiber, E. M. (1973). «Opposition to the Vietnam war among American University Students and Faculty», The British Journal of Sociology, Vol. 24, No 3, pp. 288-302.

Silverman, Jonathan (2010): Johnny Cash and American Culture. Nine choices. Boston: University of Massachusetts Press.

Stambler, Irwin y Landon, Grelun (1983). The Encyclopedia of Folk, Country and Western Music. New York: St. Martin's Press.

Stambler, Irwin y Landon, Grelun (1997). Country Music. The Encyclopedia. New York: St. Martin’s press.

Stimeling, Travis D. (2011). Cosmic cowboys and New Hicks. The countercultural sounds of Austin's progressive country music scene. New York: Oxford University Press.

Streissguth, Michael (2006). Johnny Cash. The biography. Cambridge (MA): Da Capo Press.

Streissguth, Michael (2009). Eddy Arnold: Pioneer of the Nashville sound. Jackson: University Press of Mississippi.

Tillis, Mel (1984). Stutterin' boy. New York: Rawson Associates.

Trulls, Alfonso (1994). Historia de la música country. Vol. I. Madrid: Fundamentos.

Trulls, Alfonso (1995). Historia de la música country. Vol II. Madrid: Fundamentos.

Wolfe, Charles K. y Akenson, James E. (2005). Country Music goes to war. Lexington: The University Press of Kentucky.

\section{DISCOGRAFÍA}

Advice Joe (Roy Acuff, 1951).

Ain't I right (Marty Robbins, 1966).

Amelia Earhart's Last Flight Johnnie Wright

America, Communicate with me (Ray Stevens, 1970).

Born in the USA (Bruce Springsteen, 1984).

Coming Home Soldier (Bobby Vinton y Gene Allen).

Dear Ivan (Jimmy Dean, 1961).

God please Protect America (Charlie Moore y Bill Napier, 1966).

God please Protect America (Charlie Moore y Billie Napier, 1964).

Goodbye Saigón (Billy Joel, 1982).

Have I Come To Die? (Charlie Moore y Bill Napier, 1966).

Hello Vietnam (Johnnie Wright, 1965).

I'll Be Home (Charlie Moore y Bill Napier, 1966).

I'm No Communist (Lullu Belle and Scotty, 1952).

Is This a useless War? (Charlie Moore y Bill Napier, 1966).

It's for God and Country and You, Mom (Dave McEnery, 1965).

Keep the Flag Flying (Johnnie Wright, 1965). 
Last Night I Had the strangest Dream (Ed McCurdy, 1950).

Last Night I Had the strangest Dream (Pete Seeger, 1964).

Last Night I Had the strangest Dream (John Denver, 1971).

Mister Professor (Harlan Howard, 1971).

No, No Joe (Hank Williams, 1950).

Okie from Muskogee (Merle Haggard, 1969).

Private Wilson White (Marty Robbins, 1966).

Red Deck of Cards (Dave McEnery, 1954).

Ruby, Don't Take your Love to Town (Mel Tillis, 1967).

Thank God for Victory in Korea (Jimmie Osborne, 1950).

The Ballad of the two Brothers (Autry Inman, 1968).

The Commies Are Coming (Tommy James, 1969).

The Minute Men (Are Turning in their Graves) (Stonewall Jackson, 1966).

The Red We Want is the Red We Got in the Old Red, White and Blue (Elton Britt).

The Voice of Free America (Jimmie Osborne, 1951).

They Locked God outside the Iron Curtain (Little Jimmy Dickens, 1952).

Universal Soldier (Glen Campbell, 1965).

What We're Fighting for (Dave Dudley, 1965).

Where Have all the Heroes Gone? (Bill Anderson, 1970).

Wish You Were here, Buddy (Pat Boone, 1966). 